This is the final peer-reviewed accepted manuscript of: Photocatalytic Radical Alkylation of Electrophilic Olefins by Benzylic and Alkylic Zinc-SulfinatesACS Catal. 2017, 7, 5357-5362. The final published version is available online at:

https://doi.org/10.1021/acscatal.7b01669

Rights / License:

The terms and conditions for the reuse of this version of the manuscript are specified in the publishing policy. For all terms of use and more information see the publisher's website.

This item was downloaded from IRIS Università di Bologna (https://cris.unibo.it/)

When citing, please refer to the published version. 


\title{
Photocatalytic Radical Alkylation of Electrophilic Olefins by Benzylic and Alkylic Zinc-Sulfinates
}

\author{
Andrea Gualandi, $* \$$ Daniele Mazzarella, ${ }^{\dagger}$ Aitor Ortega-Martínez, ${ }^{\ddagger}$ Luca Mengozzi ${ }^{\ddagger}$ Fabio Calcinelli, ${ }^{\star}$ \\ Elia Matteucci, ${ }^{\S}$ Filippo Monti, ${ }^{* \#}$ Nicola Armaroli, ${ }^{*}$ Letizia Sambri, ${ }^{\S}$ and Pier Giorgio Cozzi*\$ \\ ¥ Dipartimento di Chimica “G. Ciamician”, ALMA MATER STUDIORUM Università di Bologna, Via Selmi 2, 40126 \\ Bologna, Italy \\ $\S$ Dipartimento di Chimica Industriale “Toso Montanari”, ALMA MATER STUDIORUM Università di Bologna, Viale \\ Risorgimento 4, Bologna, Italy \\ \# Istituto per la Sintesi Organica e la Fotoreattività, Consiglio Nazionale delle Ricerche, Via P. Gobetti 101, 40129 Bologna, \\ Italy \\ $\dagger$ Institute of Chemical Research of Catalonia (ICIQ), Av. Països Catalans 16, 43007 Tarragona, Spain \\ \pm Departamento de Química Orgánica, Centro de Innovación en Química Avanzada (ORFEO-CINQA) and Instituto de \\ Síntesis Orgánica (ISO), Facultad de Ciencias, Universidad de Alicante, 03080 Alicante, Spain \\ KEYWORDS Sulfinates, photocatalysis, alkylation, benzylation, iridium catalysts
}

ABSTRACT: Alkyl radicals are obtained by photocatalytic oxidation of readily prepared or commercially available zinc sulfinates. The convenient benzylation and alkylation of a variety of electron-poor olefins triggered by the iridium(III) complex 6 $\left.\operatorname{Ir}\left[\mathrm{dF}\left(\mathrm{CF}_{3}\right) \mathrm{ppy}\right]_{2}(\mathrm{dtbbpy}) \mathrm{PF}_{6}\right]$ as photocatalyst is described. Moreover, it is shown that zinc sulfinates can be used for facile nonradical sulfonylation reactions with highly electrophilic Michael acceptors.

Sulfinates derivatives have been introduced in organic chemistry since the early 1900 's. ${ }^{1}$ They are a class of easily accessible or commercially available starting materials with versatile reactivity, as they can be nucleophilic or electrophilic depending on the reaction conditions. ${ }^{2}$ Many sulfinates can be readily prepared up to the kilogram scale and are stable under ambient conditions. ${ }^{3}$ Lately, oxidative conditions were applied to the generation of radical species starting from sulfinates, ${ }^{4}$ taking advantage of the fact that oxidation potentials of sulfinates are lower compared to other precursors of radicals, such as carboxylates. ${ }^{5}$ Extrusion of $\mathrm{SO}_{2}$ induced by oxidative conditions generates the corresponding aryl or alkyl radical. ${ }^{6}$ Recently, a radical-based functionalization strategy ${ }^{7}$ that involves the use of sodium and zinc bis(alkylsulfinate) reagents has been developed by Baran (Scheme 1). ${ }^{9}$ Alkyl sulfinates are also accessible by the procedures developed by Willis. ${ }^{8}$ Sulfinates have been employed in different radical-based reactions. Examples include Minisci type reactions, ${ }^{10,8 c}$ fluoroalkylation of thiols and enones ${ }^{11}$, sulfonylation of arylacetylene acids, ${ }^{12}$ and decarboxylative fluoroalkylation of $\alpha, \beta$-unsaturated carboxylic acids. ${ }^{13}$

The use of sulfinates in photoredox catalysis, where radical species are produced by an oxidation reaction induced by the photo catalyst, has been also reported. ${ }^{14}$ In particular, the photocatalytic sulfonylation of alkenes with aryl ${ }^{14 a}$ and alkyl sulfinates ${ }^{5 b}$ has been described.

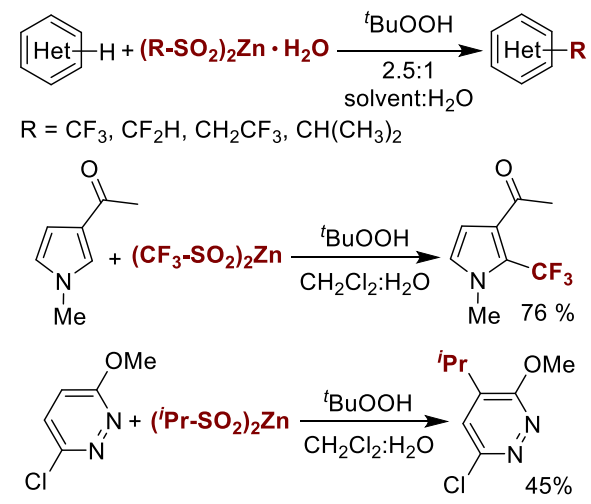

SCHEME 1. Baran's synthetic procedures with zinc sulfinate reagents.

On the other hand, benzyl- (and alkyl-) sulfinates have not been yet investigated to accomplish photocatalytic radical alkylation of electron poor olefins (Giese reaction) $)^{15}$. Indeed, the use of benzyl radicals in photoredox reactions was described by Nishibayashi ${ }^{16}$, 
Fagnoni, ${ }^{17}$ and Melchiorre,${ }^{18}$ but these intermediates are rather persistent and inefficiently trapped by Michael acceptors. As pointed out by Melchiorre, ${ }^{18}$ the large resonance stabilization of benzyl radicals hampers ready addition to electron-poor olefins, which results in the formation of dimeric bibenzyl derivatives. Therefore, Michael addition of benzylic radicals is rather difficult. Recently, a more general benzylic alkylation of Michael acceptors was reported, using mesityl-10-methylacridinium perchlorate. ${ }^{19}$ However, this strategy requires a strong oxidizing power, because benzylic radical cations are obtained by oxidation of alkylaryl derivatives $\left(\mathrm{E}_{1 / 2}{ }^{\text {red } *}\right.$ photocatalyst $=+2.06$ vs $\mathrm{SCE}$ in $\mathrm{MeCN})$.

Prompted by our interest in photoredox catalytic reactions, ${ }^{20}$ herein we describe a new procedure to accomplish the difficult radical benzylation of electrophilic alkenes, by using benzylic sufinates in combination with commercially available photocatalysts and visible light irradiation. Then, we demonstrate that the scope of the reaction can be extended by using also alkylsulfinates.

As mentioned in the introduction, benzylic sulfinates are readily accessible reagents. Indeed, sodium and zinc benzylic sulfinates were prepared by reduction of the corresponding sulfonyl chlorides. ${ }^{10}$

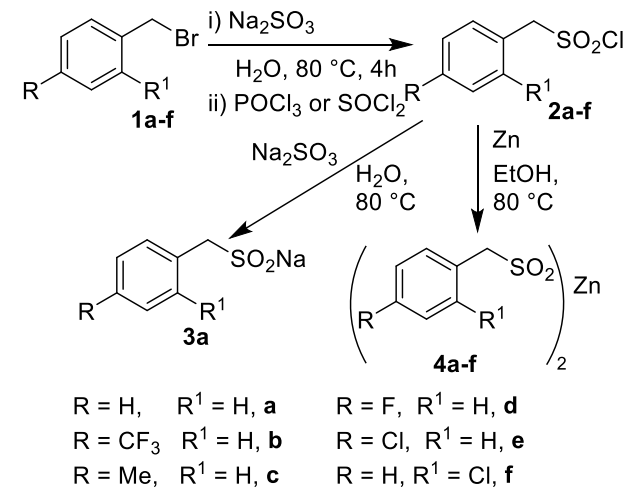

\section{SCHEME 2. Preparation of benzylic sodium (3a) and zinc sulfinates (4a-f).}

Starting from the bromide analogues, sulfonyl chlorides (2a-f) were synthesized in a two-step protocol by reaction with $\mathrm{Na}_{2} \mathrm{SO}_{3}$, followed by treatment with $\mathrm{POCl}_{3}$ or other reagents such as $\mathrm{PCl}_{5}$ or $\mathrm{SOCl}_{2}$. Sulfonyl chloride $\mathbf{2 a}$ was reduced with sodium sulfite (Scheme 2) to give the corresponding sodium sulfinate (3a). Zinc sulfinates (4a-f) were conveniently prepared from sulfonyl chlorides (2a-f) by reduction with zinc, which was activated with the Knochel procedure. ${ }^{21}$

The alkylidene malonate (5a) was chosen as model compound and the reaction with benzyl sodium sulfinate $\mathbf{3 a}$ was evaluated by varying numerous parameters in the presence of different photocatalysts (see SI for full details). Satisfactory results were generally obtained by using a mixture of EtOH or DMSO with $\mathrm{H}_{2} \mathrm{O}$ as reaction solvent, in the presence of the iridium (III) photocatalyst (6). Other photocatalysts with appropriate oxidative potential such as eosin $\mathrm{Y}^{5 \mathrm{~b}}$ or 9-mesityl-10-methylacridinium tetrafluoroborate ${ }^{22}$ gave no conversion under the examined reaction conditions.

By employing as photocatalyst the iridium(III) complex (6), the thermodynamic limit for the electron transfer between (6) and sulfinate is dictated by the excited state properties of the photocatalyst. $\left.\operatorname{Ir}\left[\mathrm{dF}\left(\mathrm{CF}_{3}\right) \text { ppy }\right]_{2}(\mathrm{dtbbpy}) \mathrm{PF}_{6}\right](\mathbf{6})$ can absorb photons in the visible spectral window, generating a powerful oxidizing excited state $\left.* \operatorname{Ir}\left[\mathrm{dF}\left(\mathrm{CF}_{3}\right) \text { ppy }\right]_{2}(\mathrm{dtbbpy}) \mathrm{PF}_{6}\right]\left(\mathrm{E}_{1 / 2} * \mathrm{III} / \mathrm{II}=+1.21 \mathrm{~V} v s\right.$ saturated calomel electrode). ${ }^{23}$

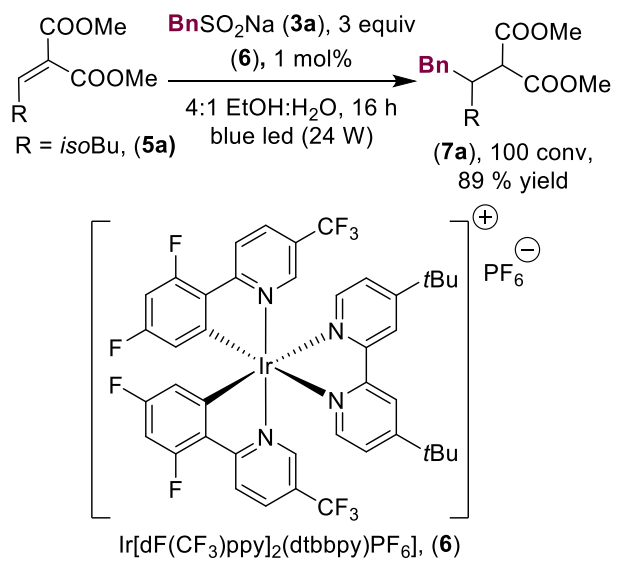

\section{SCHEME 3. Photoredox benzylation of alkylidene malonate (5a).}

The reduced $\operatorname{Ir}\left[\mathrm{dF}\left(\mathrm{CF}_{3}\right) \text { ppy }\right]_{2}$ (dtbbpy) generated by oxidative quenching is a strong reductant $\left(\mathrm{E}_{1 / 2}{ }^{\mathrm{III} / \mathrm{II}}=-1.37 \mathrm{~V}\right.$ vs saturated calomel electrode) ${ }^{23}$ Sodium alkyl sulfinates $\left(\mathrm{E}_{\text {red }}\left[\mathrm{RSO}_{2} \cdot / \mathrm{RSO}_{2}{ }^{-}\right] \approx+0.45 \mathrm{~V} \text { vs SCE}\right)^{5 \mathrm{~b}}$ are suitable substrates for the reaction. Unfortunately, even if we found satisfactory conditions (Scheme 3 ), the reaction was quite difficult to be reproduced. We found that benzylic sodium 
sulfinates were unstable, even if stored under argon at $-20{ }^{\circ} \mathrm{C}$ (see SI for details) and this was the origin of the observed problems. ${ }^{24}$ Therefore, we turned on the more stable and less reactive zinc sulfinates; although they are more difficult to be oxidized ${ }^{5 \mathrm{~b}}$ ( $\mathrm{E}_{\text {red }}$ $\left[\mathrm{RSO}_{2} \cdot / \mathrm{RSO}_{2}{ }^{-}\right] \approx+0.9 \mathrm{~V}$ vs SCE) they proved to be suitable substrates for the reaction (Table 1).

Since water was necessary to solubilize the sulfinate, we tested water miscible co-solvents. MeCN (entry 1), DMF (entry 2), TFE (entry 3) and DME (entry 4) proved unsuitable. Instead, DMSO (entry 5) showed a lower conversion rate compared to sodium sulfinate. The use of a mixture $1: 4 \mathrm{H}_{2} \mathrm{O}$ and EtOH (entry 6) gave a lower conversion compared to a 4:1 (entry 7) or 1:1 (entry 8) that afforded favorable results, with the latter being the best solvent mixture. In order to improve the solubility of the zinc reagent, coordinating species able to bind this metal were also investigated (entries 9-11). ${ }^{25}$ Unfortunately, the conversion was not improved even if zinc sulfinate seemed to be more soluble under such conditions. Finally, a good conversion was obtained with three equivalents of zinc sulfinate and 40 hours of irradiation (entry 12). With the optimized conditions in hand, a variety of electrophilic alkenes were then investigated (Scheme 4). With a variety of Michael acceptors (5b-k) the benzylated products (7b-k) were obtained in moderate to good yields. Quite interestingly, the outcome of the reaction was dependent from the alkene derivative. ${ }^{26}$ Sulfones $(\mathbf{8 m}-\mathbf{q})$ rather

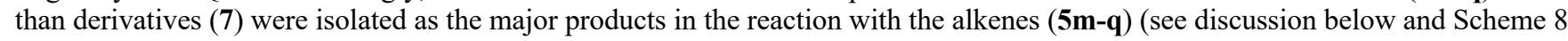
for a plausible formation mechanism).

\section{TABLE 1. Optimization of the benzylation of alkylidene $5 \mathrm{a}$ with $\left(\mathrm{BnSO}_{2}\right)_{2} \mathrm{Zn}$.}

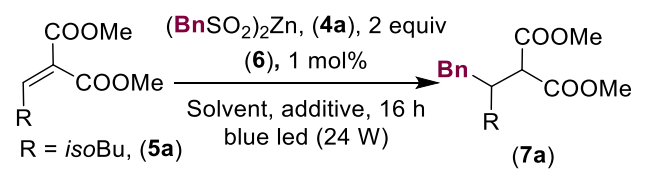

\begin{tabular}{|c|c|c|c|}
\hline Entry $^{\mathrm{a}}$ & Solvent & Additive & Yield $^{b}$ \\
\hline 1 & $\mathrm{H}_{2} \mathrm{O}: \mathrm{MeCN}(1: 1)$ & - & 25 \\
\hline 2 & $\mathrm{H}_{2} \mathrm{O}: \mathrm{DMF}(1: 1)$ & - & 58 \\
\hline 3 & $\mathrm{H}_{2} \mathrm{O}:$ TFE $(1: 1)$ & - & 31 \\
\hline 4 & $\mathrm{H}_{2} \mathrm{O}: \mathrm{DME}(1: 1)$ & - & 43 \\
\hline 5 & $\mathrm{H}_{2} \mathrm{O}: \operatorname{DMSO}(1: 4)$ & - & 74 \\
\hline 6 & $\mathrm{H}_{2} \mathrm{O}: \mathrm{EtOH}(1: 4)$ & - & 27 \\
\hline 7 & $\mathrm{H}_{2} \mathrm{O}: \mathrm{EtOH}(4: 1)$ & - & 72 \\
\hline 8 & $\mathrm{H}_{2} \mathrm{O}: \mathrm{EtOH}(1: 1)$ & - & $77(57)^{\mathrm{c}}$ \\
\hline 9 & $\mathrm{H}_{2} \mathrm{O}: \mathrm{EtOH}(1: 1)$ & $\begin{array}{l}\text { 2,6-lutidine } \\
\text { (4 equiv.) }\end{array}$ & 52 \\
\hline 10 & $\mathrm{H}_{2} \mathrm{O}: \mathrm{EtOH}(1: 1)$ & $\begin{array}{l}\text { 2,2'-bipyridine } \\
\text { ( } 2 \text { equiv.) }\end{array}$ & 72 \\
\hline 11 & $\mathrm{H}_{2} \mathrm{O}: \mathrm{EtOH}(1: 1)$ & $\begin{array}{l}\text { 1-Me-imidazole } \\
\text { (4 equiv.) }\end{array}$ & 78 \\
\hline $12^{\mathrm{d}}$ & $\mathrm{H}_{2} \mathrm{O}: \mathrm{EtOH}(1: 1)$ & - & $88(69)^{\mathrm{c}}$ \\
\hline
\end{tabular}

${ }^{a}$ All the reactions were carried out under argon. The reaction mixtures were degassed by three cycles of freeze-pump-thaw. The reactions were performed using (4a) $(0.2 \mathrm{mmol}),(\mathbf{5 a})(0.1 \mathrm{mmol})$ in $1 \mathrm{~mL}$ of solvent mixture, in the presence of $1 \mathrm{~mol} \%$ of the catalyst $\mathbf{6}$. ${ }^{\mathrm{b}}$ Determined by $1 \mathrm{H}-\mathrm{NMR}$ of the crude reaction mixture. ${ }^{c}$ In parenthesis isolated yields after chromatographic purification. ${ }^{\mathrm{d}} 3$ Equivalents of (4a) were employed and the reaction mixture was irradiated for 40 hours.

The effect of an aromatic substituent on the aryl moiety of the benzylic sulfinates derivative was explored with dimethyl fumarate as acceptor (Scheme 5).

In general, it was possible to obtain satisfactory results with a series of benzylic derivatives (4b-f), readily prepared in moderate yields by the procedure described above. In other cases, the desired zinc sulfinates compounds were not obtained (see SI for details). 


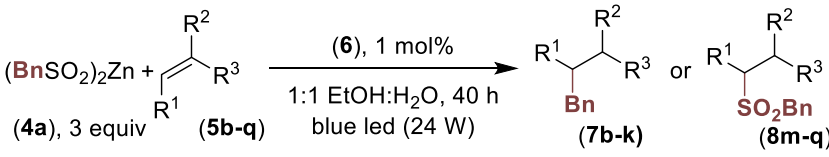

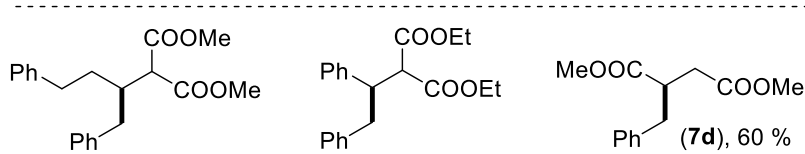

(7b), $62 \% \quad$ (7c), $11 \%$<smiles>COC(=O)CC(CCc1ccccc1)C(C)=O</smiles>

(7e), $40 \%$

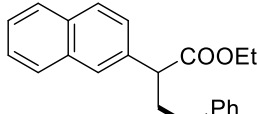

(7h), $49 \%{ }^{\mathrm{Ph}}$<smiles>CC1CCCC(=O)C1</smiles>

Ph (7k), $85 \%$<smiles>O=C(c1ccccc1)C(CS(=O)(=O)c1ccccc1)c1ccccc1</smiles>

(80), $44 \%$<smiles>COC(=O)C(CCc1ccccc1)c1ccccc1</smiles>

(7f), $40 \%$<smiles>CCCCNC(=O)CC(C)Cc1ccccc1</smiles>

(7i), $28 \%$<smiles>CC(CC(=O)N1CCOC1=O)C(=O)OCc1ccccc1</smiles>

$(8 \mathrm{~m}), 57 \%$<smiles>CC(CC(=O)c1ccccc1)C(=O)OCc1ccccc1</smiles>

(8p), $63 \%$

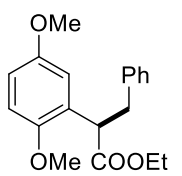

(7g), $40 \%$

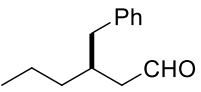

(7j), $39 \%$

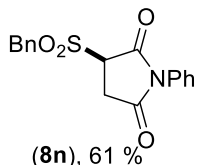

$\mathrm{BnO}_{2} \mathrm{~S} \mathrm{SO}_{2} \mathrm{Ph}$

(8q), $91 \%$

\section{SCHEME 4. Radical benzylation of different electrophilic alkenes.}

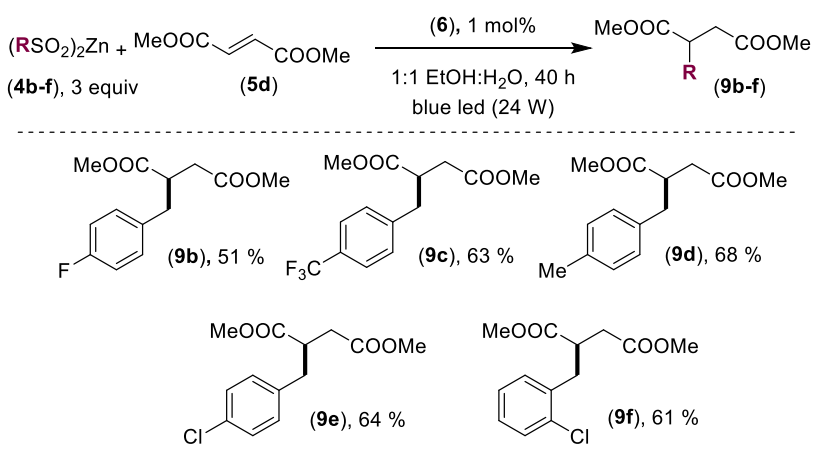

\section{SCHEMES 5. Scope of reaction with different zinc benzylic sulfinates.}

We have briefly investigated the possibility to expand the scope of the reaction by examining alkyl zinc sulfinates $(\mathbf{1 0}, \mathbf{1 1})$ which are commercially available or prepared by the general procedure (see SI for details). Although the reaction was observed, the yields of the products (12-14) were lower with respect to the benzylic sulfinates, probably due to the lower stability of the generated alkyl radicals. In the case of alkyl sulfinates, the alkene partners dictated the product obtained: sulphones $\mathbf{1 2}$ and $\mathbf{1 3}$ or alkylated adduct $\mathbf{1 4}$ (Scheme 6). ${ }^{27}$ 


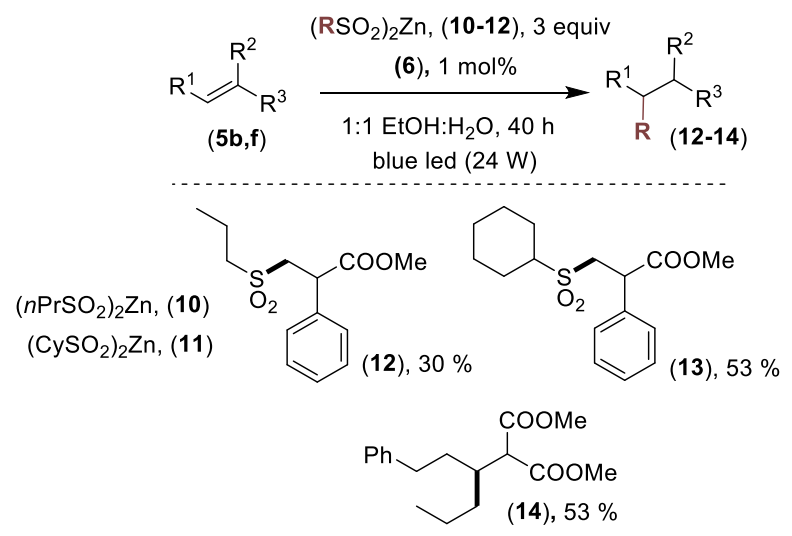

\section{SCHEME 6. Reaction of alkyl zinc sulfinates with electrophilic alkenes.}

In order to prove that the mechanism involves the formation of free radicals and that both light and photocatalyst are necessary, the model reaction was tested with 1.5 equivalents of the radical scavenger TEMPO (2,2,6,6-tetramethylpiperidin-1-yl-oxyl) (a), in absence of light (b) and without the Ir(III) catalyst (6) (c) (Scheme 7). In all cases, no conversion was observed, proving that a radical mechanism occurs and that both light and photocatalyst are necessary.

(a)

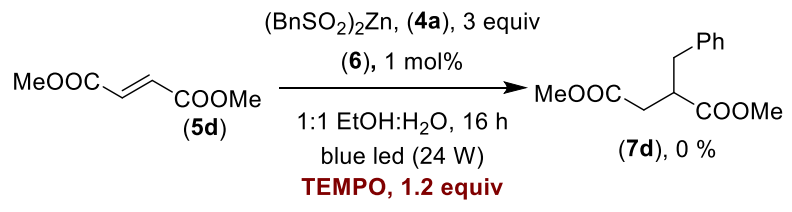

(b)

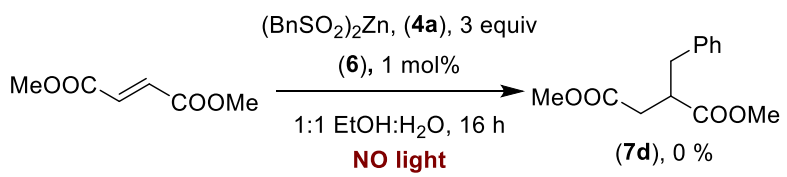

(c)

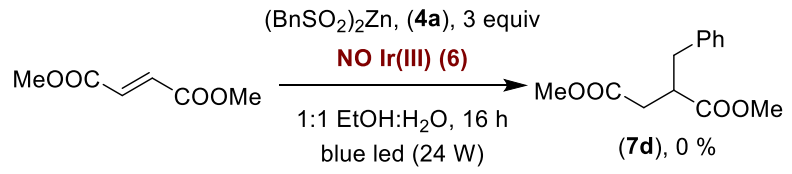

\section{SCHEME 7. Inhibition of the radical reaction in the presence of TEMPO, and in the absence of light or photocatalyst.}

The intriguing formation of sulfone derivatives $(\mathbf{8 m - q})$ and $(\mathbf{1 2}, \mathbf{1 3})$ was investigated in detail. It is important to note that only alkyland aryl-vinyl sulfones were obtained by König, using eosin Y as photocatalyst, ${ }^{5 b}$ through the addition of sulfonyl radicals to alkenes, in combination with sodium salts of alkyl and aryl sulfinates. Although the $\mathrm{SO}_{2}$ moiety is preserved with eosin, in our conditions zinc sulfinates enable the alkylation of Michael acceptors. Organosulfone mediated radical alkylation and vinylation reactions were developed by $\mathrm{Zard}^{28}$ and are centered on the facile decomposition of alkylsulfone radicals to give alkyl radical with the liberation of sulfur dioxide. ${ }^{6}$ This desulfonylation is reversible and the equilibrium is shifted if the radical is stabilized, as in our case. ${ }^{29} \mathrm{We}$ found that this process occurs also in the dark (in the absence of photocatalyst) and it is not blocked by radical scavengers (Scheme 8). Formation of sulfinyl radical ${ }^{30}$ in our conditions is unlikely to occur because reactions, in which the sulfinyl radical is formed, are completely inhibited in the presence of TEMPO. ${ }^{31}$ On the other hand, Pinnick has reported the formation of sulfones by addition of sulfinates salts (sodium, lithium, and magnesium sulfinates) to Michael acceptors. ${ }^{32}$ Zinc sulfinates are nucleophilic reagents and are able to open epoxides in water affording the corresponding $\beta$-hydroxysulfones. ${ }^{33}$ The presence of a zinc salt is probably enhancing the electrophilicity of the Michael acceptors. ${ }^{34}$

Based on these evidences, the sulfones are generated from the nucleophilic attack of the zinc sulfinates on the electrophilic alkenes partner. It is also worth mentioning that with the less electrophilic substrate (5d), no sulfone, as well as no product (7d), was isolated in the presence of TEMPO (Scheme 7 (a)). 
$\left(\mathrm{BnSO}_{2}\right)_{2} \mathrm{Zn},(4 \mathrm{a}), 3$ equiv

(a) $\mathrm{PhO}_{2} \mathrm{~S}$ NO $\operatorname{Ir}($ III) 6

(5e) $1: 1 \mathrm{EtOH}: \mathrm{H}_{2} \mathrm{O}, 16 \mathrm{~h}$ blue led $(24 \mathrm{~W})$

(8e), $100 \%{ }^{a}$

$\left(\mathrm{BnSO}_{2}\right)_{2} \mathrm{Zn},(4 \mathrm{a}), 3$ equiv

(b) $\mathrm{PhO}_{2} \mathrm{~S} \ \frac{(6), 1 \mathrm{~mol} \%}{1: 1 \mathrm{EtOH}: \mathrm{H}_{2} \mathrm{O}, 16 \mathrm{~h}} \underset{\mathrm{PhO}_{2} \mathrm{~S}}{\mathrm{SO}_{2} \mathrm{Bn}}$

$\left(\mathrm{BnSO}_{2}\right)_{2} \mathrm{Zn},(4 \mathrm{a}), 3$ equiv

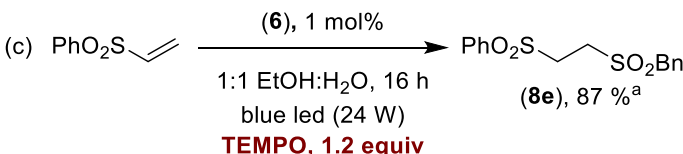

${ }^{\mathrm{a}}$ Conversions measured by ${ }^{1} \mathrm{H}-\mathrm{NMR}$ on the crude mixture.

\section{SCHEME 8. Formation of sulfones in a model reaction in different reaction conditions.}

In order to get a deeper insight into the mechanism and the efficiency of this type of photoreactions, electrochemical and photochemical studies were carried out on the iridium catalyst (6) and on the most representative reagents tested above (i.e., the benzyl zinc sulfinate $\mathbf{4 a}$, and the alkylidene malonate $\mathbf{5 a}$ ).

First of all, the redox potentials of (4a) and (5a) were characterized by square-wave voltammetry (Figure S3) and compared to the excited-state redox potential of the Ir (III) photocatalyst (6) ${ }^{30}$ In order to increase the solubility of the zinc sulfinate (4a), four equivalents of 1-methylimidazole MI were added to the acetonitrile solution. The results of the electrochemical experiments are summarized in Table 2. The redox properties of MI are also reported to demonstrate that this coordinating compound does not take part in the photochemical reaction and it simply acts as a solubilizing agent (i.e., its potentials are outside the redox window of the excited iridium photocatalyst (6), see Table 2$)$.

Table 2. Electrochemical data for the reaction partners

\begin{tabular}{lllll}
\hline & $\begin{array}{l}E_{\text {ox }} \\
{[\mathrm{V}]}\end{array}$ & $\begin{array}{l}E_{\text {red }} \\
{[\mathrm{V}]}\end{array}$ & $\begin{array}{l}E^{*}{ }_{\text {ox }} \\
{[\mathrm{V}]}\end{array}$ & $\begin{array}{l}E^{*} \text { red }^{\mathrm{a}} \\
{[\mathrm{V}]}\end{array}$ \\
\hline (4a) + MI & $+0.13^{\mathrm{b}}$ & --- & --- & --- \\
(4 equiv.) & & & & \\
(5a) & --- & $-2.42^{\mathrm{b}}$ & --- & --- \\
MI & $+1.35^{\mathrm{b}}$ & --- & --- & --- \\
(6) & +1.32 & -1.73 & $\approx-1.1$ & $\approx+0.7$
\end{tabular}

${ }^{a}$ See reference 32 for details. b Electrochemical data determined by square-wave voltammetry in room-temperature acetonitrile solution $+0.1 \mathrm{M}$ $\mathrm{TBAPF}_{6}$. All redox potentials are referred to the ferrocene/ferrocenium couple, used as internal standard. Irreversible redox process with an estimated error of $\pm 0.05 \mathrm{~V}$.

The excited-state reduction potential of the iridium complex is high enough to oxidize the benzyl zinc sulfinate (4a) (i.e., $0.7>0.13$ $\mathrm{V}$, see Table 2) and to catalyze the formation of the corresponding radical. It is worth noting that the same photocatalyst is not capable of oxidizing or reducing the alkylidene malonate (5a) (see Table 2).

The electrochemical data are supported by the Stern-Volmer quenching experiments summarized in Table 3 (see also Figure S4). As expected, the intramolecular reductive quenching of complex (6) is only observed when the benzyl zinc sulfinate (4a) is added to the photocatalyst solution. The rate constant associated to this quenching process $\left(k_{\mathrm{q}}=1.3210^{8} \mathrm{M}^{-1} \mathrm{~s}^{-1}\right.$, see Table 3$)$ is comparable to that of analogous processes involving the same iridium photocatalyst, but different oxidable radical precursors. ${ }^{20 \mathrm{c}}$

Table 3. Stern-Volmer experiments carried out in oxygen-free acetonitrile solutions at $298 \mathrm{~K}^{\mathrm{a}}$

\begin{tabular}{llc}
\hline & $K_{S V}\left[\mathrm{mM}^{-1}\right]$ & $k_{\mathrm{q}}{ }^{\mathrm{b}}\left[10^{8} \mathrm{M}^{-1} \mathrm{~s}^{-1}\right]$ \\
\hline (4a)+ MI (4 equiv.) & $0.31 \pm 0.01$ & $1.32 \pm 0.06$ \\
(5a) & Quenching not observed. ${ }^{\mathrm{c}}$ \\
MI & Quenching not observed. ${ }^{\mathrm{c}}$
\end{tabular}


${ }^{a}$ Data reported with a $\pm 95 \%$ confidence interval. In all cases, the quality of the fitting is assured by a $\mathrm{R}^{2}>0.98$. Concentration of photocatalyst: (6) $=0.015 \mathrm{mM}$; excitation wavelength: $\lambda_{\max }=330 \mathrm{~nm} .{ }^{\mathrm{b}} k_{\mathrm{q}}=K_{S V} / \tau_{0}$, where $\tau_{0}$ is the unquenched excited-state lifetime of the photocatalyst. ${ }^{\mathrm{c}}$ There is no evidence of correlation between the excited-state quenching of the photocatalyst and increasing amounts of (5a) or MI for a concentration up to $5 \mathrm{mM}$.

On the contrary, no quenching is found upon addition of $\mathbf{( 5 a )}$ or of pure 1-methylimidazole. These findings unambiguously prove that the Michael acceptor cannot directly react with (6), and that the only radicals which can be photo-catalytically produced by the Ir (III) complex are those generated by the oxidation of the zinc sulfinate derivative (4a), through C-S bond dissociation and $\mathrm{SO}_{2}$ evolution. Eventually, this radical can react with the Michael acceptor, affording a radical intermediate which can take up an electron from the photochemically reduced iridium complex. Then, the so-obtained carbanionic intermediate can be protonated, leading to the desired reaction product (7a). The mechanistic picture for the radical benzylation is illustrated in Figure 1 The proposed photocatalytic mechanism does not take into account a possible radical chain reaction. However, this process is unlikely because the quantum efficiency of the overall photochemical reaction is estimated to be $0.37 \pm 0.09$, see SI for details. ${ }^{35}$

In conclusion, we have shown that readily available zinc sulfinates could be used in photoredox catalysis producing benzylic radicals in an oxidative quenching cycle. The benzylic radicals could be intercepted by suitable Michael acceptors. With strong electrophilic Michael acceptors, zinc sulfinates can behave as nucleophiles leading to the corresponding sulfone derivative, without radical formation.

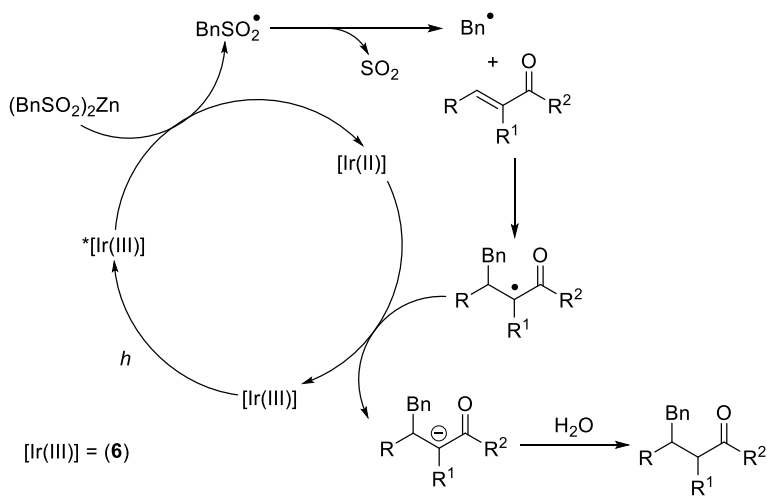

FIGURE 1. Suggested mechanism for the benzylation reaction with zinc sulfinates.

\section{ASSOCIATED CONTENT}

Supporting Information. Screening tests. Photophysical measurements and quenching studies. Detailed procedures, description and copies of NMR spectra for all compounds. This material is available free of charge via the Internet at http://pubs.acs.org

\section{AUTHOR INFORMATION}

\section{Corresponding Authors}

* Dipartimento di Chimica “G. Ciamician” ALMA MATER STUDIORUM, Università di Bologna Via Selmi 2, 40126, Bologna, Italy. Email: andrea.gualandi10@unibo.it; piergiorgio.cozzi@unibo.it. \# Istituto per la Sintesi Organica e la Fotoreattività, Consiglio Nazionale delle Ricerche, Via P. Gobetti 101, 40129 Bologna, Italy. Email: filippo.monti@enr.it.

\section{ORCID}

Andrea Gualandi: 0000-0003-2403-4216

Daniele Mazzarella: 0000-0001-7121-9796

Aitor Ortega-Martínez: 0000-0002-8211-4479

Luca Mengozzi: 0000-0003-4472-1400

Elia Matteucci: 0000-0003-4206-817X

Filippo Monti: 0000-0002-9806-1957

Nicola Armaroli: 0000-0001-8599-0901

Letizia Sambri: 0000-0003-1823-9872

Pier Giorgio Cozzi: 0000-0002-2677-101X.

\section{Author Contributions}

The manuscript was written through contributions of all authors. All authors have given approval to the final version of the manuscript. A. G. was involved in the discovery and development of the photochemical reaction. A. G., D. M., A. O.-M., F. C. and L. M. performed the experiments. E. M. and L. S. prepared the $\operatorname{Ir}(\mathrm{III})$ complexes used for the studies. F. M. and N. A. designed and performed the photophysical measurements. P. G. C. conceived and directed the project and wrote the manuscript with contributions from all the authors.

\section{Funding Sources}


Bologna University, Fondazione Del Monte, SLAMM project are acknowledged for financial support to A G. and L. M. N.A. and F.M. thank the CNR for financial support through the projects PHEEL, N-CHEM, and bilateral CNR-CONICET.

\section{ACKNOWLEDGMENT}

A. O.-M. thanks the Spanish MINECO for a fellowship.

\section{ABBREVIATIONS}

Zinc trifluoromethanesulfinate (TFMS), zinc difluoromethanesulfinate (DFMS), zinc trifluoroethanesulfinate (TFES) and zinc isopropylsulfinate (IPS), tetrabutylammonium decatungstate (TBADT), trimethylsilyl (TMS), saturated calomel electrode (SCE), acetonitrile (MeCN), dimethylsufoxide (DMSO), 2,2,6,6-tetramethylpiperidin-1-yl-oxyl (TEMPO),

\section{REFERENCES}

(1) (a) Borsche, W.; Lange, W. Ber. Dtsch. Chem. Ges. 1906,

39, 2346; (b) Smiles, S.; Le Rossignol, R. J. Chem. Soc. Trans. 1908, 93, 745.

(2) For a review, see: Aziz, J.; Messaoudi, S.; Alami, M.; Hamze, A. Org. Biomol. Chem. 2014, 12, 9743

(3) O'Hara, F.; Baxter, R.D.; O'Brien, A.G.; Collins, M.R.; Dixon, J.A.; Fujiwara, Y.; Ishihara, Y.; Baran, P. S., Nature Protocols $2013,8,1042$.

(4) Wu, W. Q.; Yi, S. J; Yu, Y.; Huang, W.; Jiang, H. F. J. Org. Chem. 2017, 82, 1224-1230.

(5) (a) For hexanoate; $\mathrm{E}^{\text {red }}{ }_{1 / 2}=+1.16$ vs SCE; see: Galicia, M.; Gonzales, F. J. J. Electrochemical Soc. 2002, 149, D.46. (b) For sodium alkyl sulfinates;

$\mathrm{E}^{\mathrm{red}} 1 / 2=+0.45$ V vs SCE; see: Uwe Meyer, A.; Strakov, K.; Slanina,T.; König, B. Chem. Eur. J. 2016, 22, 8694;

(6) Chatgilialoglu, C.; Lunazzi, L.; Ingold, K. U. J. Org. Chem. 1983,48, 3588-3589.

(7) (a) A. Studer, D. P. Curran Angew. Chem. Int. Ed. 2016, 55, 58; (b) Yan, M.; Lo, J. C.; Edwards, J. T.; Baran, P. S. J. Am. Chem. Soc. 2016, 138, $12692-12714$

(8) Yan, M.; Lo, J. C.; Edwards, J. T.; Baran, P. S. J. Am. Chem. Soc. 2016, 138, 12692. For other radical reactions developed by Baran group, see: a) Ji, Y.; Brueckl, T.; Baxter, R.D.; Fujiwara, Y.; Seiple, I.B.; Su, S.; Blackmond, D.G.; Baran, PNAS, 2011, 108, 14411; (b) Fujiwara, Y.; Dixon, J.A.; Rodriguez, R.A.; Baxter, R.D.; Dixon, D.D.; Collins, M.R.; Blackmond, D.G.; Baran, P.S. J. Am. Chem. Soc. 2012, 134, 1494; (c) Fujiwara, Y.; Dixon, J.A.; O'Hara, F.; Daa Funder, E.; Dixon, D.D.; Rodriguez, R.A.; Baxter, R.D.; Herlé, B.; Sach, N.; Collins, M.R.; Ishihara, Y.; Baran, P.S. Nature 2012, 492, 95; (d) Zhou, Q.; Ruffoni, A.; Gianatassio, R.; Fujiwara, Y.; Sella, E.; Shabat, D. ; Baran, P.S. Angew. Chem. Int. Ed. 2013, 52, 3949; (e) O'Hara, F.; Blackmond, D.G.; Baran, J. Am. Chem. Soc. 2013, 135, 12122; (f) Zhou, Q.; Gui, J.; Pan, C.-M.; Albone, E.; Cheng, X.; Suh, E.M.; Grasso, L.; Ishihara, Y.; Baran, P.S. J. Am. Chem. Soc. 2013, 135, 12994; (g) Gui, J.; Zhou, Q.; Pan, C.-M.; Yabe, Y.; Burns, A. C.; Collins, M. R.; Ornelas, M. A.; Ishihara, Y.; Baran, P. S. J. Am. Chem. Soc. 2014, 136,4853

(9) (a) Flegeau, E. F.; Harrison, J. M.; Willis, M. C. Synlett, 2016, 27, 101; (b) Emmett,E. J.: Willis, M. C. Asian J. Org. Chem. 2015, 4, 602; (c) Deeming, A. S. ; Russell, C. J. Willis, M. C. Angew. Chem. Int. Ed. 2015, 54, 1168; (d) Deeming, A. S.; Emmett, E. J.; Richards-Taylor, C. S.; Willis, M. C. Synthesis, 2014, 46, 2701; (e) Deeming, A. S.; Russell, C. J.; Hennessy, A. J.; Willis, M. C. Org. Lett. 2014, 16, 150; (f) Richards-Taylor, C. S.; Blake-more, D. C.; Willis, M. C. Chem. Sci. 2014, 5, 222.

(10) Minisci, F.; Fontana, F.; Vismara, E. J. Heterocycl. Chem. 1990, 27, 79

(11) Ni, C.; Hu, M.; Hu, J. Chem. Rev. 2015, 115, 765.

(12) Meesin, J.; Katrun, P.; Pareseecharoen, C.; Pohmakotr, M.; Reutrakul, V.; Soorukram, D.; Kuhakarn, C J. Org. Chem. 2016, $81,2744$.

(13) (a) Li, Z., Cui, Z.; Liu, Z.-Q. Org. Lett. 2013, 15, 406;

(14) (a) Meyer, A. U.; Jäger, S.; Hari, D. P.; König, B. Adv. Synth. Catal. 2015, 357, 2050; (b) Meyer, A. U.; Lau, V. W. H.; König, B. ; Lotsch, B. V. Eur. J. Org. Chem. 2017, 2179; (c)Hering, T.; Uwe Meyer, A.; König, B. J. Org. Chem. 2016, 81, 6927, and ref. therein.

(15) Giese, B.; Gonzalez-Gomez, J. A.; Witzel, T. Angew. Chem. Int. Ed. Engl. 1984, 23, 69-70. For a quite recent example, see: Qin T.; Malins, L. R.; Edwards, J. T.; Merchant, R. R.; Novak, A. J. E.; Zhong, J. Z.; Mills, R. B.; Yan, M.; Yuan, C.; Eastgate, M. D.; Baran, P. S. Angew. Chem. 2017, doi: 10.1002/anie.201705107

(16) Miyake,Y.; Nakajima, K.; Nishibayashi, Y. Chem. Commun. 2013, 49, 7854.

(17) Capaldo, L.; Buzzetti, L.; Merli, D.; Fagnoni, M.; Ravelli, D. J. Org. Chem. 2016, 81, 7102.

(18) Silvi, M.; Verrier, C.; Rey, R. Y.; Buzzetti, L.; Melchiorre, P. Nature Chem. 2017, DOI: 10.1038/NCHEM.2748.

(19) Zhou, R.; Liu, H.; Tao, H.; Yu, Y.; Wu, J. Chem. Sci. 2017, DOI: 10.1039/C7SC00953D.

(20) (a) Gualandi, A.; Marchini, M.; Mengozzi, L.; Natali, M.; Lucarini, M.; Ceroni, P.; Cozzi, P. G. ACS Catal. 2015, 5, 5927; (b) Magagnano, G.; Gualandi, A.; Marchini, M.; Mengozzi, L.; Ceroni, P.; Cozzi P. G Chem. Commun. 2017, 53, 1581; (c) Gualandi, A.; Matteucci, E.; Monti, F.; Armaroli, N.; Sambri, L.; Cozzi, P. G. Chem. Sci. 2017, 8, 1613.

(21) Chang, P.; Yeh, P.; Chen, H. G.; Knochel P. Org. Synth. 1992, 70, 195.

(22) Fukuzumi, S.; Kotani,H.; Ohkubo,K.; Ogo, S.; V. Tkachenko, N. V.; Lemmetyinen, H. J. Am. Chem. Soc. 2004, $126,1600$.

(23) Lowry, M. S.; Goldsmith, J. I.; Slinker, J. D.; Rohl, R.; Pascal, R. A.; Maliaras, G. G.; Bernhard, S. Chem. Mat. 2005, 17, 5712.

(24) ${ }^{1} \mathrm{H}-\mathrm{NMR}$ signal of sodium sulfinates stored in air at r.t. were showing the presence of other species after few hours. Also, storing the sample at -20 ${ }^{\circ} \mathrm{C}$ the decomposition was only delayed. See SI for an image.

(25) For coordination of zinc sulfonates with a nitrogen containing heterocycle, see: Lindner, E.; Frembs, D. W. R.; Krug, D. Chem. Ber. Chem. Ber. $1975,108,291$.

(26) Mayr has measured the electrophilicity of Michael acceptors in a series papers; see: (a) Chen, Q.; Mayer, P.; Mayr, H. Angew. Chem. Int. Ed. 2016, 55, 12664; (b) Allgäuer, D. S.; Mayr, H. Eur. J. Org. Chem. 2014, 2956; (c) Asahara, H.; Mayr, H. Chem. Asian J. 2012, 7, 1401 (d) Zenz, I.; Mayr, H. J. Org. Chem. 2011, 76, 9370; (e) Kaumanns, O.; Lucius, R.; Mayr, H. Chem. Eur. J. 2008, 14, 9675. Although these kinetic investigations, a general method to predict the corresponding reactivities and selectivities of Michael acceptors is still missing. However, the relative reactivities of different families of Michael acceptors can be obtained by the thermodynamics of the rate-determining step, as was recently found by Mayr: H. Mayr, personal communication

(27) For the reduction potential and LUMO energy of a series of $\alpha, \beta$-unsaturated compounds, see: Moraleda, D.; El Abed, D.; Pellissier, H.; Santelli, M. THEOCHEM 2006, 760,113-119. Recently, the computational study of the addition of benzyl radical, generated through photoredox conditions was reported: see Tutkovsky, B.; Meggers, E.; Wiest, O. J. Am. Chem. Soc. 2017; DOI: 10.1021/jacs.7b01786. The LUMO of the electron deficient alkene substrate and the SOMO of the benzyl radical acting as a nucleophile are the orbitals involved in the process. The energy of the orbitals and their full structures were reported in the article.

(28) a) Bertrand, F.; Quiclet-Sire, Z.; Zard, S. Z. Angew. Chem. Int. Ed. 1999, 38, 1943; (b) Quiclet-Sire, B.; Zard, S. Z. Beilstein J. Org. Chem. 2013 $9,557$.

(29) Kim, S.; Kim, S. Bull Soc. Chim. Jpn. 2007, 80, 809.

(30) (a) Chatgilialoglu, C.; Mozziconacci, O.; Tamba, M.; Bobrowski, K.; Kciuk, G.; Bertrand, M. P.; Gastaldi, S.; Timokhin, V. I. J. Phys. Chem. A 2012, 116, 7623; (b) Chatgilialoglu, C. in The chemistry of Sulfone and Sulfoxides, eds. S. Patai, Rapaport, Z, Stirling, J. J. M. Wiley, Chichester 1988, pp. 1089. 
(31) (a) Huang, Z.; Lu, Q.; Liu, Y.; Liu, D.; Zhang, J.; Lei, A. Org. Lett. 2016, 18, 3940; (b) Chen, F.; Meng, Q.; Han, S.-Q.; Han, B.; Org. Lett. 2016, 18,3390 .

(32) Pinnick, H. W.; Reynolds, M. A. J. Org. Chem. 1979, 44, 160.

(33) Chumachenko, N.; Sampson, P. Tetrahedron 2006, 62, 4540-4548.

(35) The measured value of the quantum yield is similar to that found in a photoredox radical decarboxylation reaction: Y. Miyake, Nakajima, K.; Nishibayashi, Y. Chem. Commun. 2013, 49, 7854. 